\title{
Analysis on the Female Unemployment in the United States
}

\author{
Hong Qiu ${ }^{1, *}$ \\ ${ }^{1}$ Shen Wai International School, Shenzhen, China, 518000 \\ ${ }^{*}$ Corresponding author. Email: 22.irina.qiu@swis.cn
}

\begin{abstract}
Currently, over the past few years, more than 2.3 million women have left the labor force, and by comparison, there are only 1.8 million men who have left the labor force over the same time period. Women unemployment are still in crisis as a social factor that the world needs to consider seriously. Women have been facing issues such as gender discrimination and some unfair treatments among the society, they have been considered as the vulnerable group, for those women who want to work are facing issues such as having harder time to find a job than men. Some common examples could be seen like the female group not being hired, and even get lower-paying positions due to the gender identity or the sexual orientation, which leads those social issue of being held to certain higher standards. This paper will focus on the issue of female unemployment in the United States, giving persuasive information about the unfair social issues that women have been facing. Based on different social factors that have caused women unemployment, this paper will analyses the ways and measures that the society can take in order to improve the situation will be concluded in this paper.
\end{abstract}

Keywords: feminism movement, employment of female, gender discrimination, gender equality

\section{INTRODUCTION}

Throughout the COVID-19 pandemic, it has had a negative impact especially on female unemployment but there are different stages of crisis due to specific gender segregation. Women's labor force participation still feels more compared to men. Over the course of the first 10 months of the coronavirus, women has become particularly the group of women has lost their job. Women have lost a net of 5.4 million jobs during the recession, women have lost nearly 1 million more jobs compared to men. For example, the job loss in December can be represent as a trend, for those women who are black, Hispanic, and Asian has been accounted for all of women's job loss for that specific month. Due to statistic report, 154,000 black women has dropped out their labor force entirely. Job loss has been pushed due to this issue, some legislation such as creating robust care infrastructure, ensuring fair and equal wages and quality benefits, and also creating strong workplace protections. If those legislations haven't been set and conduct, women's status will be further damaging [1].

Before the coronavirus pandemic has been induced, the economic needs can not be satisfied, this has been a reality issue for many women and their families. Statistics can prove that there are around 21.4 million women living under the difficult situation of poverty in the year of 2018 to 2019 [1]. However, women's work has always been undervalued for a long time. There are long-standing gender biases and situations such as inequality has appeared to the issue such as segregation between women into low-wage jobs, also gaps due to different women's race and biases in ethics.

This paper will discuss the female employment situation especially in the United States. The female group among the society has been facing many unequal and unfair treatments, discriminations appears towards the female gender. Different jobs and workplaces refuse to hire female groups more than that to men. This paper will be covering issues that they are currently facing and those unequal treatment they are getting from society.

\section{LAWS THAT PROTECT WOMEN RIGHTS IN THE US}

There are certain laws and rules to protect women's rights during the job unemployment situations, essential actions have been set for the granger quotable recovery. In the US, gender discrimination has been explicitly 
outlawed under Title VII of the Civil Rights Act of 1964, which is a federal law that in order to prevents employee not discrimination specifically on race, color, religion, sex and national origin. This landmark labor law has been given nationwide protections for employee in different job situation, but the discrimination among different sex is still exists.

Under the federal law, gender discrimination among unemployment is illegal, but currently there are no federal workplace which protects employees who are discriminated against on gender identity and sexual orientation. Many states across the U.S defines gender and sex discrimination differently under their respective law. Many states courts, agencies, commissions and attorney generals has chosen to interpret the existence of federal law on gender discrimination protections in order to include protection measures against discrimination on the account of gender identity and different sexual orientation. Gender and sex discrimination in workplaces has became illegal under federal laws within the passing journey of the Civil Rights Act of 1964. This law provides protections to individuals who are currently applying for jobs and employees in their current workplace [2].

\section{FACTORS ANALYSIS ON FEMALE EMPLOYMENT}

\subsection{Unequal employment opportunities for women}

Although statistics show that the proportion of female students in colleges and universities in China has reached $44 \%$, basically holding up "half the sky" on campus, the employment opportunities of female students are far lower than that of male students. In the process of hunting for a job, gender discrimination is one of the serious issue which are becoming a more stumbling block for female graduates. Pregnancy are one of the main factor which are common factor to gender discrimination, include childbirth and breastfeeding, in addition to certain types of gender prejudices which has lead to employer to exclude females.

\subsection{Unequal retirement age and pension benefits}

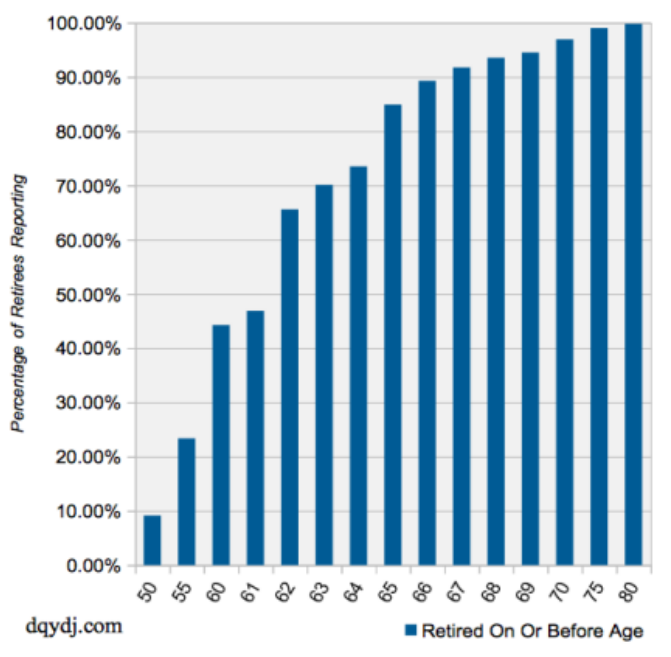

Figue 1 The cumulative American retirees by age [3]

Note: 2017 Federal reserve survey of household economics and decisionmaking

It is a factual and legal problem of gender discrimination in China that men and women do not retire at the same age. Figure 1 shows the cumulative American retirees by age. Most foreign countries implement the same age retirement system for both men and women, whether in developing countries (such as India) or developed countries (such as the European Union). It cannot be denied for those group of retirement age, there are difference between men and women as two different gender, which was originally designed to take care of women, and it was once been considered a symbol of women's rights and interests. No matter how, we cannot deny the development of our society and the continuous improvements of modern science and technology, also the continuous improvement of female education level and education quality. This provision can undergone the qualitative changes, which is has already changed from the original protection of women rights to compulsory restrictions.

\subsection{Men and women receive different payments for the same work}

It is a harsh reality that men and women are paid differently for equal work in different industries. Generally speaking, in addition to education level, the key factor determining income level should be a person's ability. According to a special study, female 
students are self-disciplined, hardworking and resilient, and their chances of getting a job, promotion and salary increase are no worse than men's.

Some experts believe that women also have some problems. In addition to improving their knowledge and skills, bravely fighting for their rights and interests is also the bottleneck that women need to break through.

There are wage gaps for each job based on gender discrimination, especially for females. Several factors has caused the gender wage gap, such as the different cues in industries or jobs worked, certain job has fixed their payment to male and female with different wage, especially in companies with less gender protection, some of them does not have enough awareness about how important it is to lower the wag between wage.

\subsection{Gender segregation of posts}

Due to the influence of traditional industry and traditional ideas, employers choose job seekers based on gender, which obviously forms a separate situation between male and female jobs, resulting in gender segregation of positions.

From the perspective of female employment structure, horizontal: between industries, female work is mostly the social extension of family role. Vertical: As you move up the management ladder, there are fewer women. The ceiling phenomenon not only exists in enterprises, but also in state institutions [4].

\subsection{Discrimination in job situations}

To be clarify with gender discrimination among women and specifically affecting them in workplace, which could also be understand as a form of discrimination that women has been treated differently or unfairly due to the basis of a person's sex.

There are different factors which affect the female unemployment situation in the US, among working situations, discrimination to the female gender group has directly influence the life of female group. Disparate treatment based on sex can generally be understand as the different and unfair treatment to employees on the basis of their different sex. Employees in different work situations may have experienced this when hiring and selecting employees. Harness and gender discrimination towards women could also be very obviously seen also form the sexual harassment in workplace [5]. The range can be from sexual jokes, the use of sexual slurs and non-consensual touching. Moreover, some female employees often need more holidays to deal with their personal affairs due to the particularity of their physical quality. Therefore, it will also lead to serious damage to the interests of many companies. In particular, some female employees reach a certain age when they need to have children. This results in women having to take long periods of maternity leave. Although the law stipulates that female employees can have reasonable maternity leave. But in fact, many companies do not pay attention to this aspect of women's rights, which leads to many women losing their jobs because of pregnancy. As a result, many companies are reluctant to hire more women in order to maintain stability. In addition, male employees are more physically advantageous, so some jobs that require physical labor cannot be done by female employees. Therefore, in the development of modern society, male employees have far more job opportunities than female employees. In addition, the current global economic downturn has led to a large number of female suitable industries in the downturn. So this also makes some female friends often appear at home unemployed.

\section{DIFFICULTIES THAT FEMALE IS CURRENTLY FACING}

Those women who want and are willing to work and are having a harder time finding jobs than men, and females are more likely to have a hard time in the workplace situation. Women also tend to be over represented in certain types of vulnerable jobs, according to the perspective of social working situations. Gender roles are a big issue, such as the pressure to conform those job roles for different women across their different religions, regions and even households. One of the pressures that society gives to women is their marital status. Especially in developing countries, economic necessity in those regions has given all women very little choice but to be in those working conditions despite their female marital status. To balance their work and family is also a challenge, for both women and men, they all report that the biggest issue for female unemployment is having the balance between job and their family responsibilities.

There are works such as childcare, cleaning and cooking that are very necessary for a household's welfare, so in this condition the well-being of societies will be as a whole. For developing regions and countries, there is a lack of safety and accessible transportations which could be considered the most challenging factor for the small percentage that some women cannot have a job which leads to female unemployment. Also, female faces the issue that having sexual harassment and even sexual assault on their daily commute. According to other global statistics, there appears to be a lack of affordable care for children to their family members and it is an obstacle for women, both for those who are looking for a job and those in the job situation with payments. 


\section{SUGGESTIONS ON IMPROVING WOMEN EMPLOYMENT RATE}

Public citizens always wonder why women lose more jobs in the workplace, and there is more unemployment that could be seen in the gender of females. This is because women have a congenital disadvantage in physical condition compared with men. In addition, the current global economy has been in a very depressed state, so many companies will choose to retain more important jobs in order to save costs. And we see that in some important jobs, men are far more dominant than women. So when companies have to lay off workers in order to survive, women are more vulnerable. So that's why the unemployment rate for women is now much higher than for men [6].

\subsection{Suggestions to women themselves}

As women themselves, protection of own rights is necessary. Women needs to speak for themselves when they are not been treating equally in job situations. In the united states, women in a same space can form into groups, and take measure to solve the issue between gender wage gap. Parad could be one of the example for women to take action, they should let the world know about their voice, and show the society how unequal they have been treat.

\subsection{Suggestions to the government}

According to the discrimination situation appeared in the society, government should pay more attention in issues like this. Certain regulations might be helpful, for example, direct regulation and policies could help. If government set laws related the job area, companies will focus more on the aspect of protecting female rights, provide equal rights among differnet gender. As the government in the country, unite everyone is im[portant, such as collaborate with certain NGOs, take actions to advertise how important it is to have equal rights between differnet genders, ethical issues need to be take into consideration, it is very important for governments to raise people's awareness about treating women equally, such as in different job space.

\section{CONCLUSION}

As the voices of society grows more and more, legal circles which against the female employment discrimination has changed from explicit discrimination to certain gender into implicit discrimination. However, implicit discrimination are more difficult to be noticed and eliminated, which will lead the anti-female employment discrimination even harder to be noticed and eliminated, which will make the task of anti-female employment discrimination more difficult. Discrimination which against female is also different in various of fields among female employment, in different jobs and indifferent stages after female employment.

In order to solve the issue and let the gap between gender unemployment decrease, the society can take certain measures such as to identify and quantify those barriers that currently occur, which can allow the government to develop a smarter policy; closing the gender gaps in labor force is not just good for women, for their whole households, but also good for the global economy as a whole. However, as the society as a whole is developing, every community should take action in order to provide female rights. Different age group, male community, different culture group, and people in different region with different beliefs should raise their awareness on the issue of female unemployment. In order to achieve this, the most effective way is to take action from ourself in daily life, and change this issue as a global citizen.

\section{AUTHORS' CONTRIBUTIONS}

This paper is independently completed by Hong Qiu.

\section{ACKNOWLEDGMENTS}

Thanks to my professor and teacher who helped me with this research paper, guided me through the whole journey, checked over my outlines and helped me set the topics.

\section{REFERENCES}

[1] Phadke, D. B. and S. (n.d.). When women lose all the Jobs: Essential Actions for a gender-equitable recovery. Center for American Progress. Retrieved October 30, 2021, from https://www.americanprogress.org/issues/women/r eports/2021/02/01/495209/women-lose-jobsessential-actions-gender-equitable-recovery/.

[2] How gender discrimination affects women in the workplace. Florin. (2021, September 3). Retrieved October 30, 2021, from https://florinroebig.com/workplace-discriminationwomen/

[3] PK. Average Retirement Age in the United States. June 3rd, 2018. https://dqydj.com/averageretirement-age-in-the-united-states/

[4] Law Express. What are the manifestations of female employment discrimination? June 28, 2020. https://in9nbo.smartapps.cn/pages/knowledgeDetai 1?url=laodong_funvbaohu_20140307142020\&_sw ebfr=1\&_swebFromHost=baiduboxapp

[5] Status of women. Women's Labor Force Participation. 2014. https://statusofwomendata.org/earnings-and-the- 
gender-wage-gap/womens-labor-force-

participation/

[6] Monthly unemployment rate of women in the United States from September 2020 to September 2021.Published by Statista Research Department, Oct 11 , 2021. https://www.statista.com/statistics/193298/unadjust ed-unemployment-rate-of-women-in-the-us/ 